\section{Original article}

\title{
Aetiology of urethral discharge in Bangui, Central African Republic
}

\author{
P Morency, M J Dubois, G Grésenguet, E Frost, B Mâsse, S Deslandes, P Somsé, \\ A Samory, F Mberyo-Yaah, J Pépin
}

Objectives: To determine the aetiology of urethritis in Bangui, Central African Republic. Methods: 410 men presenting with urethral discharge and 100 asymptomatic controls were enrolled. Urethral swabs were obtained and processed by gonococcal culture and polymerase chain reaction for the detection of Neisseria gonorrhoeae, Chlamydia trachomatis, Mycoplasma genitalium, Trichomonas vaginalis, and Ureaplasma urealyticum.

Results: In multivariate analyses, $M$ genitalium and $C$ trachomatis were significantly associated with urethral discharge when comparing cases of non-gonococcal urethritis (NGU) with controls. T vaginalis was also more common in cases than in controls, but this reached statistical significance only among cases in whom $N$ gonorrhoeae was also detected. U urealyticum was not associated with urethritis. The gonococcus was found in $69 \%$ of cases of urethral discharge. $M$ genitalium was the predominant pathogen in patients with NGU, being found in $42 \%(53 / 127)$ of such patients while $C$ trachomatis was found in only $17 \%(22 / 127) . T$ vaginalis was found in $18 \%$ $(23 / 127)$ of patients with NGU, but also in $15 \%$ (43/283) of patients with gonococcal urethritis, and two thirds of patients with $T$ vaginalis also had the gonococcus. Multiple infections were common. $M$ genitalium caused a syndrome similar to chlamydial urethritis, with a less severe inflammation than in gonococcal infection. No behavioural or clinical characteristic could discriminate between the various aetiological agents.

Conclusions: $M$ genitalium is more prevalent than $C$ trachomatis and is the most common cause of NGU in Bangui. It causes a syndrome similar to chlamydial urethritis. $T$ vaginalis is weakly associated with urethritis, and is often found along with other pathogens.

(Sex Transm Inf 2001;77:125-129)

Keywords: urethritis; Central African Republic; Mycoplasma genitalium

\section{Centre for \\ International Health, \\ University of \\ Sherbrooke, Canada \\ $P$ Morency \\ M J Dubois \\ E Frost \\ $S$ Deslandes \\ J Pépin}

Centre National de

Référence pour les

Maladies Sexuellement

Transmissibles,

Bangui, Central

African Republic

G Grésenguet

A Samory

Centre de Recherche,

CHA-Pavillon

St-Sacrement,

Québec, Canada

B Mâsse

Ministry of Public

Health, Bangui,

Central African

Republic

P Somsé

F Mberyo-Yaah

Correspondence to:

Dr Jacques Pépin, Centre for

International Health, 3001,

12ème Avenue Nord,

Sherbrooke, Québec J1H

$5 \mathrm{~N} 4$, Canada

jpepin01@courrier.usherb.ca

Accepted for publication

13 December 2000

\section{Introduction}

Sexually transmitted diseases (STD) facilitate the transmission of HIV. This interaction may be a major factor in the rapid spread of HIV in sub-Saharan Africa. A study in Tanzania demonstrated that strengthening STD management in primary healthcare centres resulted in a $42 \%$ reduction in the transmission of HIV. ${ }^{1}$ This has given a new impetus to national STD control programmes. Control strategies focus on the syndromic management of STD with cheap but effective drugs, following standardised flow charts. ${ }^{23}$ At the national level, it is important to obtain reliable data on the aetiology of major STD syndromes, to ensure that the flow charts perform well in the local context but also to develop strategies for patients whose symptoms have not improved despite proper use of the recommended drugs. Little information is available on the aetiology of STD syndromes in central Africa. We conducted a study of the aetiology of urethral discharge in Bangui, Central African Republic (CAR), which examined the role of genital mycoplasmas and of Trichomonas vaginalis, in addition to the more conventional gonococci and chlamydia.

\section{Methods}

From July 1996 to January 1997, all male patients presenting with a complaint of urethral discharge at the Centre National de Référence pour les Maladies Sexuellement Transmissibles (CNRMST) in Bangui were invited to participate in the study, which had been ethically approved by the Ministry of Public Health. The CNRMST is the national STD centre, and offers STD care to patients living in the Bangui area (approximately half a million inhabitants). Some patients are referred to the CNRMST by other healthcare providers, but the majority come on their own, either for the first treatment of their STD or because treatment obtained elsewhere has failed. $\mathrm{Pa}$ tients who agreed to participate were administered a questionnaire looking at sociodemographic characteristics, sexual behaviour, past STD, and current symptoms. A genital examination was performed by a doctor who also obtained urethral samples. Gram stain and culture for Neisseria gonorrhoeae (NG) were performed at the CNRMST on specimens obtained as routinely done in this clinic (patients were not systematically asked not to have urinated within the previous 4 hours). Cultures for NG were performed on a modified Thayer-Martin medium and identification was based on the Gram stain and oxidase test.

A urethral swab was also obtained for polymerase chain reaction (PCR) analyses, put into the Amplicor transport medium (Roche Diagnostic Systems), and kept refrigerated until its transport to Canada. PCR was carried out for the following potential pathogens: Neisseria gonorrhoeae, Chlamydia trachomatis (CT), 
Trichomonas vaginalis (TV), Mycoplasma genitalium (MG), and Ureaplasma urealyticum (UU). Specimens were prepared for PCR by adding an equal volume of Amplicor specimen diluent, and kept at least 3 days at $4^{\circ} \mathrm{C}$ before analysis to reduce the frequency of inhibition. ${ }^{4}$ Inhibition was monitored in samples negative for all pathogens by Amplicor internal control or a home brew internal control made by cloning the MG amplicon and inserting a DNA fragment. ${ }^{45}$ For NG and CT, the Roche Amplicor Chlamydia trachomatis/Neisseria gonorrhoeae Test Kit (Roche Diagnostic Systems) was used according to the manufacturer's instructions. Modifications of the procedures of Jensen for $M$ genitalium, of Blanchard and Willoughby for $U$ urealyticum and of Shaio for $T$ vaginalis were employed. ${ }^{6-10}$ Primers used for MG, UU, and TV are shown in table 1. Each micro-organism was revealed separately using PCR (U urealyticum) or seminested PCR (M genitalium, $T$ vaginalis) and detection of the amplicon after electrophoresis through agarose gels and staining with ethidium bromide. A prepared sample $(25 \mu \mathrm{l})$ was added to a master mix $(25 \mu \mathrm{l})$ composed of $2 \times$ buffer $20 \mathrm{mM}$ TRIS-HCl pH 8.3, $100 \mathrm{mM} \mathrm{KCl,} 400 \mu \mathrm{M}$ of dNTP, 1.25 unit of Taq polymerase, and 0.5 $\mu \mathrm{M}$ primers. The amplification procedure was 5 minutes at $95^{\circ} \mathrm{C}$ and 40 cycles of denaturation $\left(95^{\circ} \mathrm{C}\right)$, annealing $\left(62^{\circ} \mathrm{C}\right)$, and extension $\left(72^{\circ} \mathrm{C}\right)$ for 20 seconds at each step. After holding the samples at $72^{\circ} \mathrm{C}$ for 15 minutes, the reactions were cooled to $4^{\circ} \mathrm{C}$. After the first series, a seminested series of PCR was undertaken using $1 \mu \mathrm{l}$ of the first series and 49 $\mu \mathrm{l}$ of a master mix to give the same final concentration of reagents as the initial series.

To investigate the association between potential pathogens and the urethral discharge syndrome, urethral swabs were also obtained from 100 adult male patients consulting in a Bangui health centre for complaints unrelated to the genital tract (mostly febrile syndromes attributed to malaria). These specimens were processed for PCR as for patients with urethral discharge, but no Gram stain and no culture for NG were carried out. Data were entered on EPI-INFO 6.0 and analysed with EPI-INFO and STATA 5.0. Proportions were compared with the $\chi^{2}$ test or Fisher's test when appropriate. Continuous data were compared with the Student's $t$ test or the Wilcoxon rank sum test. For multivariate analysis, a logistic regression analysis was carried out.

\section{Results}

PCR was performed on all 410 patients with a complaint of urethral discharge but, owing to security problems in Bangui during the study period, we were able to perform cultures for NG on only 344 of them. Of these 344 patients, 223 were positive in both the culture and the PCR, 86 were negative in both, 26 were positive in NG PCR and negative in culture, and only nine were positive in culture and negative in PCR. We were able to confirm, with a 16S rRNA PCR (supplied by Roche Diagnostic Systems), 22 of the 26 samples positive with the Amplicor PCR but negative in culture. A patient was considered to have gonococcal urethritis if either the culture or the Amplicor PCR (or both) was positive for NG. However, for the unmatched case-control analysis, since gonococcal cultures were not available for asymptomatic controls, only patients with a positive NG PCR were considered to have gonococcal infection. For all other potential pathogens, a positive PCR was the only criterion to determine the presence of the agent.

In table 2 are compared the distribution of the five potential pathogens in 410 cases with urethral discharge and in 100 asymptomatic controls. In univariate analyses NG, CT, and TV were found significantly more often in cases of urethral discharge than in asymptomatic controls; $M G$ was also found more frequently in cases than in controls, but this did not reach statistical significance. UU was found significantly more often in controls than in cases. As controls were younger (median 23 versus 25 years, $p<0.001$ ) and had had fewer sex partners in the past 12 months than cases (median 1 versus 4 sex partners, $\mathrm{p}<0.001$ ), factors which were themselves related to the prevalence of potential pathogens, and as there was a substantial number of multiple infections, a logistic regression analysis was carried out in which the odds ratios for each potential pathogen were adjusted for other pathogens but also for age and the number of sex partners in the past 12 months. It revealed a significant interaction between NG and MG and thus we present in table 2 results of univariate and

Table 1 Polymerase chain reaction primers for the detection of Mycoplasma genitalium, Ureaplasma urealyticum, and Trichomonas vaginalis

\begin{tabular}{|c|c|c|c|}
\hline Organism & Target & Primers & Sequence \\
\hline Mycoplasma genitalium & $140 \mathrm{kDa}$ adhesin gene & $\begin{array}{l}\text { outer primers } \\
M G \text { PA1 } \\
M G \text { PA3 } \\
\text { inner primer used } \\
\text { with MG PA1 } \\
M G \text { PA2 }\end{array}$ & $\begin{array}{l}\text { TTGATGAAACCTTAACCCCTTGG } \\
\text { GTTGAGGGGTTTTCCATTTTTGC } \\
\text { GACCATCAAGGTATTTCTCAACAGC }\end{array}$ \\
\hline Ureaplasma urealyticum & urease gene & $\begin{array}{l}U U 9 \mathrm{~A} \\
U U 4 \mathrm{AR}\end{array}$ & $\begin{array}{l}\text { AGGAGATAATGATTATATGTCAGG } \\
\text { CGAAACGACGTCCATAAGCAAC }\end{array}$ \\
\hline Trichomonas vaginalis & $650 \mathrm{bp}$ repetitive sequence & $\begin{array}{l}\text { outer primers } \\
T V \text { rep1 } \\
T V \text { rep2R } \\
\text { inner primer used } \\
\text { with TVrep2R } \\
T V \text { rep3 }\end{array}$ & $\begin{array}{l}\text { AATTGGAACCAGTGTCAGAATAC } \\
\text { CCCATTCTTTTAGACCCTTCAG } \\
\text { ATACAAAACATCCCCAACATCTT }\end{array}$ \\
\hline
\end{tabular}


Table 2 Distribution of potential aetiological agents recovered by PCR in urethral swabs of cases with urethral discharge and in asymptomatic controls. Percentages (and absolute numbers) with a given micro-organism are shown as well as odds ratios (OR) and adjusted odds ratios (AOR) and their $95 \%$ confidence intervals

\begin{tabular}{|c|c|c|c|c|}
\hline & \multirow[b]{2}{*}{$\begin{array}{l}\text { Controls } \\
(n=100)\end{array}$} & \multirow[b]{2}{*}{$\begin{array}{l}\text { All cases of urethral discharge } \\
(n=410)\end{array}$} & \multicolumn{2}{|l|}{ According to presence of $N G$} \\
\hline & & & $\begin{array}{l}\text { Urethral discharge positive } \\
\text { for } N G(n=274) t\end{array}$ & $\begin{array}{l}\text { Urethral discharge negative } \\
\text { for } N G(n=136) \emptyset\end{array}$ \\
\hline N gonorrhoeae & $9.0 \%$ & $\begin{array}{l}66.8 \% \\
\text { OR: } 20.37(9.96-41.64) \ddagger\end{array}$ & & \\
\hline$C$ trachomatis & $6.0 \%$ & $\begin{array}{l}13.7 \% \\
\text { OR: } 2.48(1.03-5.93)^{\star}\end{array}$ & $\begin{array}{l}12.4 \% \\
\text { OR: } 2.22(0.90-5.46) \\
\text { AOR: } 2.50(0.76-8.16)\end{array}$ & $\begin{array}{l}16.2 \% \\
\text { OR: } 3.02(1.18-7.76)^{\star} \\
\text { AOR: } 4.63(1.41-15.18)^{\star}\end{array}$ \\
\hline$T$ vaginalis & $7.0 \%$ & $\begin{array}{l}16.1 \% \\
\text { OR: } 2.55(1.13-5.74)^{\star}\end{array}$ & $\begin{array}{l}15.7 \% \\
\text { OR: } 2.47(1.07-5.70)^{\star} \\
\text { AOR: } 2.81(1.02-7.76)^{\star}\end{array}$ & $\begin{array}{l}16.9 \% \\
\text { OR: } 2.70(1.11-6.58)^{\star} \\
\text { AOR: } 1.97(0.71-5.52)\end{array}$ \\
\hline$M$ genitalium & $15.0 \%$ & $\begin{array}{l}20.5 \% \\
\text { OR: } 1.46(0.80-2.66)\end{array}$ & $\begin{array}{l}9.9 \% \\
\text { OR: } 0.62(0.31-1.22) \\
\text { AOR: } 0.56(0.24-1.33)\end{array}$ & $\begin{array}{l}41.9 \% \\
\text { OR: } 4.09(2.14-7.80) \ddagger \\
\text { AOR: } 4.40(2.05-9.46) \ddagger\end{array}$ \\
\hline U urealyticum & $48.0 \%$ & $\begin{array}{l}34.6 \% \\
\text { OR: } 0.57(0.37-0.89)^{\star}\end{array}$ & $\begin{array}{l}29.9 \% \\
\text { OR: } 0.46(0.29-0.74) \ddagger \\
\text { AOR: } 0.24(0.13-0.46) \ddagger\end{array}$ & $\begin{array}{l}44.1 \% \\
\text { OR: } 0.86(0.51-1.44) \\
\text { AOR: } 0.74(0.38-1.44)\end{array}$ \\
\hline
\end{tabular}

Odds ratios and $\mathrm{p}$ values correspond to comparisons between appropriate category of cases and controls; ${ }^{\star} \mathrm{p}<0.05 ; \neq \mathrm{p} \leqslant 0.001$.

†Adjusted in a logistic regression model for all controls and cases positive for NG, which included CT, TV, MG, UU, age, and number of sex partners in past 12 months.

ๆAdjusted in a logistic regression model for all controls and cases negative for NG, which included the same variables as above.

multivariate analyses after stratification of cases according to whether NG was present or not. MG was associated with urethral discharge only in the absence of NG. For CT, the association with urethritis was stronger and statistically significant only among those cases negative for NG. For TV, the association reached statistical significance only among patients with NG. UU was clearly not associated with urethral discharge. The following analyses will examine NG, CT, MG, and TV to better delineate their contribution to urethral discharge in Bangui, but the role of UU will not be further examined.

Table 3 Combinations of pathogens in cases of urethral discharge

\begin{tabular}{lllll}
\hline $\begin{array}{l}\text { Pathogen (number of } \\
\text { specimens) }\end{array}$ & $\begin{array}{l}\text { Neisseria } \\
\text { gonorrhoeae }\end{array}$ & $\begin{array}{l}\text { Chlamydia } \\
\text { trachomatis }\end{array}$ & $\begin{array}{l}\text { Trichomonas } \\
\text { vaginalis }\end{array}$ & $\begin{array}{l}\text { Mycoplasma } \\
\text { genitalium }\end{array}$ \\
\hline N gonorrhoeae $(\mathrm{n}=283)$ & $\mathbf{6 7 . 1 \% ( 1 9 0 )}$ & $12.0 \%(34)$ & $15.2 \%(43)$ & $11.0 \%(31)$ \\
C trachomatis $(\mathrm{n}=56)$ & $60.7 \%(34)$ & $\mathbf{2 5 . 0 \% ( 1 4 )}$ & $14.3 \%(8)$ & $21.4 \%(12)$ \\
T vaginalis $(\mathrm{n}=66)$ & $65.2 \%(43)$ & $12.1 \%(8)$ & $\mathbf{1 9 . 7 \% ( 1 3 )}$ & $21.2 \%(14)$ \\
$M$ genitalium $(\mathrm{n}=84)$ & $36.9 \%(31)$ & $14.3 \%(12)$ & $16.7 \%(14)$ & $\mathbf{4 7 . 6 \% ( 4 0 )}$ \\
\hline
\end{tabular}

Totals add up to over $100 \%$ because some subjects have multiple infections; numbers in bold are the proportions and absolute numbers of single infections.

Table 4 Prevalence of pathogens in cases of urethral discharge (single and multiple infections) according to behavioural, clinical, or laboratory characteristics

\begin{tabular}{|c|c|c|c|c|c|}
\hline & $\begin{array}{l}\text { Neisseria } \\
\text { gonorrhoeae }\end{array}$ & $\begin{array}{l}\text { Chlamydia } \\
\text { trachomatis }\end{array}$ & $\begin{array}{l}\text { Trichomonas } \\
\text { vaginalis }\end{array}$ & $\begin{array}{l}\text { Mycoplasma } \\
\text { genitalium }\end{array}$ & $\begin{array}{l}\text { None of these } \\
\text { four pathogens }\end{array}$ \\
\hline \multicolumn{6}{|l|}{ Previous treatment } \\
\hline Yes $(n=198)$ & $65.2 \%$ & $12.1 \%$ & $13.6 \%$ & $20.2 \%$ & $12.1 \%$ \\
\hline No $(n=208)$ & $72.1 \%$ & $14.9 \%$ & $18.3 \%$ & $21.2 \%$ & $10.1 \%$ \\
\hline \multicolumn{6}{|c|}{ Acquired from sex worker } \\
\hline Yes $(n=306)$ & $74.2 \%$ & $14.7 \%$ & $15.4 \%$ & $19.6 \%$ & $7.2 \%$ \\
\hline No $(n=101)$ & $52.5 \% \dagger$ & $8.9 \%$ & $17.8 \%$ & $23.8 \%$ & $22.8 \% \dagger$ \\
\hline \multicolumn{6}{|l|}{ Duration of discharge } \\
\hline $1-7$ days $(n=215)$ & $80.5 \%$ & $12.6 \%$ & $16.3 \%$ & $15.8 \%$ & $5.6 \%$ \\
\hline $8-14$ days $(n=85)$ & $70.6 \%$ & $15.3 \%$ & $14.1 \%$ & $23.5 \%$ & $8.2 \%$ \\
\hline$\geqslant 15$ days $(n=110)$ & $45.5 \% \dagger$ & $14.5 \%$ & $17.3 \%$ & $27.3 \% \star$ & $23.6 \% \dagger$ \\
\hline \multicolumn{6}{|l|}{ Any discharge seen } \\
\hline Yes $(n=385)$ & $71.7 \%$ & $14.0 \%$ & $16.6 \%$ & $20.8 \%$ & $8.3 \%$ \\
\hline No $(n=24)$ & $25.0 \% \dagger$ & $8.3 \%$ & $4.2 \%$ & $12.5 \%$ & $54.2 \% \dagger$ \\
\hline \multicolumn{6}{|l|}{ Purulent discharge seen } \\
\hline Yes $(n=303)$ & $82.8 \%$ & $11.9 \%$ & $14.5 \%$ & $14.9 \%$ & $5.3 \%$ \\
\hline No $(n=103)$ & $28.2 \% \dagger$ & $18.4 \%$ & $20.4 \%$ & $35.0 \% \dagger$ & $28.2 \% \dagger$ \\
\hline \multicolumn{6}{|c|}{ PMNs/field on Gram stain } \\
\hline$\geqslant 5(n=275)$ & $86.2 \%$ & $13.5 \%$ & $15.6 \%$ & $16.7 \%$ & $1.5 \%$ \\
\hline $1-4(n=38)$ & $28.9 \%$ & $23.7 \%$ & $21.1 \%$ & $28.9 \%$ & $28.9 \%$ \\
\hline $0(\mathrm{n}=17)$ & $47.1 \% \dagger$ & $17.6 \%$ & $5.9 \%$ & $35.3 \% \star$ & $23.5 \% \dagger$ \\
\hline \multicolumn{6}{|c|}{ Gram negative diplococci } \\
\hline Present $(n=236)$ & $98.7 \%$ & $10.6 \%$ & $14.4 \%$ & $10.2 \%$ & $0.4 \%$ \\
\hline Absent $(n=94)$ & $24.5 \% \dagger$ & $25.5 \% \star$ & $19.1 \%$ & $41.5 \% \dagger$ & $19.1 \% \dagger$ \\
\hline
\end{tabular}

Totals for each characteristic vary because of missing values; ${ }^{\star} \mathrm{p}<0.05 ; \mathrm{tp}<0.001$.
Among the 410 patients with urethral discharge, 69\% (283) had gonococcal urethritis (from now on defined as PCR and/or culture positive), $14 \%$ (56) had a chlamydial infection, 20\% (84) harboured $M$ genitalium, 16\% (66) had $T$ vaginalis recovered, while $11 \%$ (45) were negative for all four pathogens. CT was found in $17 \%(22 / 127)$ of patients with a nongonococcal urethritis and in $12 \%(34 / 283)$ of those with a gonococcal urethritis $(p=0.20)$. MG was found in $42 \%(53 / 127)$ of patients with non-gonococcal urethritis, compared with $11 \%(31 / 283)$ in men with gonococcal urethritis $(\mathrm{p}<0.001)$. TV was as frequent in patients with non-gonococcal $(18 \%, 23 / 127)$ as in those with gonococcal $(15 \%, 43 / 283)$ urethritis $(\mathrm{p}=0.55)$. Table 3 shows the co-infections in patients with urethral discharge; $153(37 \%)$ of the 410 cases had more than one pathogen detected. While NG and MG were found on their own in, respectively, $67 \%$ and $48 \%$ of patients in whose samples these pathogens were documented, CT and TV were usually recovered along with other micro-organisms. CT, MG, and TV were equally frequent as co-infections in patients with gonococcal urethritis. TV was strongly associated with NG. Of all patients with TV recovered, two thirds also had NG, while one fifth also had MG, and only one fifth had TV as the sole "pathogen". CT was also strongly associated with NG.

Overall, $49 \%$ of patients had sought treatment elsewhere before coming to the $\mathrm{CN}$ RMST: $56 \%$ of this subgroup had bought drugs from peddlers in markets, $21 \%$ in pharmacies, and $19 \%$ in health centres. Table 4 shows the prevalence of the four pathogens according to various behavioural or clinical characteristics. There was no significant difference in the prevalence of any of these four micro-organisms between patients who had received previous treatment and patients for whom the visit to the CNRMST was the first attempt to get treatment; this suggests that, despite the CNRMST being a reference institution, its population of patients was roughly representative of urethritis patients in 
Bangui. Attributing the current urethritis to contact with a sex worker increased the probability that NG (but not other pathogens) would be recovered. A discharge was observed during the clinical examination in $94 \%$ of patients; among those without a discharge, the gonococcus was found in a quarter and almost half had at least one pathogen recovered. Patients with a purulent discharge and patients with a discharge lasting less than 2 weeks were more likely to have NG and less likely to have MG than others. Even though $86 \%$ of men with $\geqslant 5$ polymorphonuclear leucocytes (PMNs) per field had NG, 35\% (19/55) of patients who did not fulfil this objective criterion of urethritis also had NG. Patients whose urethritis was not acquired from a sex worker, those with a discharge lasting for more than 2 weeks, without any discharge observed, without a purulent discharge or with less than 5 PMNs per field and patients without Gram negative diplococci on the urethral smear were all more likely to have no pathogen recovered. A review of the clinical characteristics of patients with a single pathogen recovered showed that those with CT, MG, or TV urethritis had identical clinical syndromes, with a less severe and longer lasting urethritis than patients among whom NG was found (data not shown).

\section{Discussion}

Two thirds of patients seeking treatment for urethral discharge in Bangui had evidence of gonococcal infection. This is in line with reports from other African countries where $N$ gonorrhoeae is the aetiological agent in $53-80 \%$ of cases of urethritis. ${ }^{11}$ Only $12 \%$ of patients with gonococcal urethritis in Bangui were found to have concomitant CT infection. PCR should have been more sensitive than the methods (cultures, ELISA) used in previous studies on the African continent, but we cannot exclude the possibility of underdetection of CT due to inhibition of CT PCR in patients with symptomatic gonococcal infection. ${ }^{12} \mathrm{CT}$ was also rather uncommon as an aetiological agent of non-gonococcal urethritis (NGU): only $17 \%$ of these patients had CT documented in their samples. This paucity of $C$ trachomatis infection is comparable with other reports from African countries where $C$ trachomatis was involved in only $3-16 \%$ of cases of NGU and was found concomitantly in only $3-12 \%$ of cases of gonococcal urethritis. ${ }^{11} 1314$ This contrasts with developed countries where $11-34 \%$ of male patients with gonorrhoea also have $C$ trachomatis infection and where $C$ trachomatis is the aetiological agent in $15-58 \%$ of cases of NGU. ${ }^{15}$

Mycoplasma genitalium has recently been identified as an agent of NGU in Western Europe. ${ }^{16-18} \mathrm{MG}$ was a much more common cause of NGU in Bangui than $C$ trachomatis, being found in $42 \%$ of such patients. We thus confirmed our recent finding from seven west African countries that $M$ genitalium is an aetiological agent of NGU in Africa, ${ }^{10}$ and indeed its contribution to this syndrome seems to be more prominent in central Africa than in west
Africa. As our observations depend on a home brew PCR, we confirmed our results by digesting the amplicon with the restriction endonuclease Sau3A I and precisely sizing by polyacrylamide gel electrophoresis the two restriction fragments predicted from the sequence. This PCR does not amplify reference strains of Mycoplasma pneumoniae, U urealyticum, or Mycoplasma hominis at high concentrations, nor Canadian genital samples that were positive by culture for the latter two microorganisms. It readily detected 10 copies of the positive control $M$ genitalium target sequence cloned in the plasmid pUC 19 even when they were spiked into NG positive samples.

The characteristics of MG urethritis in Africa are similar to what is observed with chlamydial urethritis. MG induces a less severe urethral inflammation than NG, so that patients are less likely to have a purulent discharge and to complain of dysuria while waiting longer before seeking treatment. It seems likely that many of these patients remain sexually active during this period. Thus, MG could have some impact on HIV transmission, as recently suggested by a study in American heterosexual couples, ${ }^{19}$ even though its effect on the urethral shedding of HIV might be more modest than that of $\mathrm{NG}^{20}{ }^{20}$ The severe inflammation induced by the gonococcus may prompt the patient to discontinue sexual activity and to find an appropriate treatment more rapidly than with MG. There is unfortunately little information on the optimal treatment of MG urethritis, but it seems likely that a 7 day course of doxycycline would be adequate for most cases. ${ }^{21}$ The current WHO recommended syndromic management of urethral discharge, which consists of a single dose treatment for gonorrhoea (generally with ciprofloxacin) and a 1 week course of doxycycline, ${ }^{2}$ is probably effective in patients infected with MG and does not need to be reconsidered.

The contribution of TV to the urethral discharge syndrome in Bangui is unclear. It was found in $16 \%$ of cases of urethral discharge, a prevalence similar to what we and others found in west Africa (14\%) and Malawi $(21 \%){ }^{10}{ }^{22}$ $\mathrm{TV}$ is also found in $6-12 \%$ of asymptomatic men. ${ }^{10}{ }^{22}$ In west Africa, TV was found significantly more often in cases of urethral discharge than in asymptomatic controls after adjustment for other pathogens and various confounders, ${ }^{10}$ whereas in the current study this difference did not reach statistical significance. This may simply be due to a somewhat smaller sample size, as the adjusted odds ratios were similar in both studies (2.62 in west Africa, 2.81 and 1.97 in Bangui). However, as in the west African study, TV was usually recovered along with other micro-organisms and was the sole pathogen in only $13(3 \%)$ patients with urethritis in Bangui. In cases of co-infections, further studies will be required to delineate if TV contributes to the inflammation or is merely a co-transmitted innocent bystander. In the meantime, it seems unwarranted to systematically add metronidazole as a first line drug in all patients with urethral discharge, but this drug 
should be considered in patients whose discharge persists after having received ciprofloxacin and doxycycline, especially since a recent study showed that patients with TV urethritis have higher levels of seminal HIV shedding than asymptomatic controls. ${ }^{22}$ Although TV is probably the most frequent sexually transmitted pathogen in women, ${ }^{23}$ it is not clear that treating men harbouring $\mathrm{TV}$ in their urethra would impact on TV in women by decreasing the reservoir.

Our results show that the syndromic approach is the only rational way to deal with patients presenting with urethral discharge in sub-Saharan Africa. At least three, and probably four, pathogens are involved in the aetiology of urethral discharge, and multiple infections are common. Furthermore, there is substantial overlap between urethritis of various aetiologies with regard to the clinical presentation. Thus, the simultaneous treatment of all patients for gonorrhoea (preferably with ciprofloxacin), CT, and MG (with doxycycline) seems the only logical way to deal with this problem. Drugs potentially active against these three pathogens (azithromycin, ofloxacin) are unfortunately too expensive to be considered at the present time. Future aetiological studies should focus on patients who have failed first line therapy, to define rational second line algorithms and clarify the role of $T$ vaginalis.

In Bangui, having received a previous treatment had no effect on the prevalence of various pathogens. This merely reflects the dismal quality of STD care in this city, especially in the informal sector where treatment with ineffective drugs are the rule rather than the exception. ${ }^{24}$ Unless the syndromic approach is used not only in government health centres but in the informal sector where most STD patients seek care, the potential impact of STD control on the spread of HIV will remain a missed opportunity.

This study received the financial support of the Canadian International Development Agency through the Canadian Bureau for International Education. We are indebted to Dr Michel Alary for advice and to Désiré Méga for assistance in data collection.

Contributors: PM, MJD, GG, PS, JP conceived the study; PM, Contributors: PM, MJD, GG, PS, JP conceived the study; PM,
MJD, FM-Y, PS, GG were responsible for data collection; EF MJD, FM-Y, PS, GG were responsible for data collection; EF,
SD, AS carried out the laboratory investigations; JP, BM, PM carried out the statistical analyses; JP wrote the first draft of the manuscript and all authors contributed to subsequent versions.

1 Grosskurth H, Mosha F, Todd J, et al. Impact of improved treatment of sexually transmitted diseases on HIV infection
in rural Tanzania: randomised controlled trial. Lancet in rural Tanzania:
2 World Health Organization. Management of sexually transmitted diseases. WHO/GPA/TEM/94 1. Geneva: WHO, 1994.

3 Dellabetta GA, Gerbase AC, Holmes KK. Problems, solutions and challenges in syndromic management of sexually transmitted diseases. Sex Transm Inf 1998;74 (Suppl 1):S1-11.

4 Toye B, Woods W, Bobrowska M, et al. Inhibition of PCR in genital and urine specimens submitted for Chlamydia trachomatis testing. F Clin Microbiol 1998;36:2356-8.

5 Frost EH, Deslandes S, Bourgaux-Ramoisy D, et al. Quantitation of Chlamydia trachomatis by culture, direct immunofluorescence and competitive polymerase chain reaction. Genitourin Med 1995;71:239-43.

6 Jensen JS, Uldum SA, Sondergard-Andersen J, et al. Polymerase chain reaction for detection of Mycoplasma genitalium in clinical samples. F Clin Microbiol 1991;29:4650 .

7 Blanchard A, Hentschel J, Duffy L, et al. Detection of Ureaplasma urealyticum by polymerase chain reaction in the urogenital tract of adults, in amniotic fluid, and in the respiratory tract of newborns. Clin Infect Dis 1993;17(Suppl 1):S148-53.

8 Willoughby JJ, Russell WC, Thirkell D, et al. Isolation and detection of urease genes in Ureaplasma urealyticum. Infect Immun 1991;59:2463-9.

9 Shaio MF, Lin PR, Liu JY. Colorimetric one-tube nested PCR for detection of Trichomonas vaginalis in vaginal discharge. 7 Clin Microbiol 1997;35:132-8.

10 Pépin J, Sobela F, Deslandes S, et al. Aetiology of urethral discharge in west Africa: the role of Mycoplasma discharge in west Africa: the role of Mycoplasma
genitalium and Trichomonas vaginalis. Bull World Health Organ 2001;79:118-26.

11 Goeman J, Meheus A, Piot P. L'épidémiologie des maladies sexuellement transmissibles dans les pays en développement à l'ère du SIDA. Ann Soc Belg Med Trop 1991;71:81113.

12 Van der Pol B, Quinn TC, Gaydos CA, et al. Multicenter evaluation of the AMPLICOR and automated COBAS AMPLICOR CT/NG tests for detection of Chlamydia trachomatis. F Clin Microbiol 2000;38:1105-12.

13 Lule G, Behets FMT, Hoffman IF, et al. STD/HIV control in Malawi and the search for affordable and effective urethritis therapy: a first field evaluation. Genitourin Med 1994;70:384-8.

14 Tyndall M, Nasio J, Maitha G, et al. Leukocyte esterase urine strips for the screening of men with urethritis-use in urine strips for the screening of men with urethritis

15 Martin DH, Bowie WR. Urethritis in males. In: Holmes KK, Sparling PF, Mardh PA, Lemon SM, Stamm WE, Piot P, Wasserheit JN, eds. Sexually transmitted diseases. New York: McGraw-Hill, 1999.

16 Taylor-Robinson D. The history and role of Mycoplasma genitalium in sexually transmitted diseases. Genitourin Med 1995;71:1-8.

17 Horner PJ, Gilroy CB, Thomas BJ, et al. Association of Mycoplasma genitalium with acute non-gonococcal urethritis. Lancet 1993;342:582-5.

18 Jensen JS, Orsum R, Dohn B, et al. Mycoplasma genitalium: a cause of male urethritis? Genitourin Med 1997;69:265-9.

19 Perez G, Skurnick JH, Denny TN, et al. Herpes simplex type II and Mycoplasma genitalium as risk factors for heterosexual HIV transmission: report from the Heterosexual HIV Transmission Study. Int f Infect Dis 1998;3:511 .

20 Cohen MS, Hoffman IF, Royce RA, et al. Reduction of concentration of HIV-1 in semen after treatment of urethritis: implications for prevention of sexual transmission of HIV-1. Lancet 1997:349:1868-73

21 Gambini D, Decleva I, Lupica L, et al. Mycoplasma genitalium in males with nongonococcal urethritis. Prevalence and clinical efficacy of eradication. Sex Transm Dis 2000;27:226-9.

22 Hobbs MM, Kazembe P, Reed AW, et al. Trichomonas vaginalis as a cause of urethritis in Malawian men. Sex Transm Dis 1999;26:381-387.

23 Gerbase AC, Rowley JT, Heymann DHL, Berkley SFB, Piot P. Global prevalence and incidence estimates of selected
curable STDs. Sex Transm Inf 1998;74(Suppl 1):S12-16.

24 Somsé P, Mberyo-Yaah F, Morency P, et al. Quality of STD treatments in the formal and informal sectors in Bangui, Central African Republic. Sex Transm Dis 2000;27:458-64. 